\title{
Bacteriological Quality of Drinking Water and Diarrhoeal Outcome among Under Five Children in Resettlement Colony, Delhi: A Community-based Study
}

\author{
Risa Vernette N Sangma, SK Rasania, JG Prasuna, Ranjan Das, Manoj Jais \\ Department of Community Medicine \\ Lady Hardinge Medical College, New Delhi \\ vernetty@gmail.com; skrasania@gmail.com; Prasuna.josyula@gmail.com; ranjandas1986@gmail.com; \\ drmanojjais@yahoo.co.in
}

\begin{abstract}
Globally, diarrhoea is the second leading cause of death among under five children and India alone accounts for 100,000 lives annually, third highest in the world. In low and middle-income countries, contaminated water has been the major source of diarrhoea. It has been seen that lack of improper WaSH (Water, Sanitation and Hygiene) practices accounts for $90 \%$ of the total death due to diarrhoea. Objective: To determine the bacteriological quality of drinking water and diarrhoeal morbidity among under five children and to assess the WaSH (Water, Sanitation and Hygiene) practices among children and mothers/care givers. Materials and Methods: A community based cross-sectional study conducted in resettlement colony, Kalyanpuri of Delhi. A total of 553 under five children were studied after attaining consent from mothers/care givers. MPN count per 100 ml was measured from point source as well as drinking water storage vessel. Result: Prevalence of diarrhoea was found to be $40.2 \%$ in the period between January 2018 to December 2018. It was found to be more prevalent among children aged between 13-24 months (57.3\%). On assessing the bacteriological quality of water samples, $37 \%$ of samples were unsatisfactory, $36 \%$ suspicious and $22 \%$ satisfactory. None of the samples were found to be satisfactory. On assessing the WaSH practices, it was observed that the mother/care givers lacked the knowledge and importance of hand hygiene and sanitation practices. Conclusion: Diarrhoea being a preventable disease yet takes a heavy toll of lives of children. Mere awareness without behaviour change cannot reduce the burden of diarrhoea. Education on WaSH practices, their acceptance and also on household water treatment and storage practices can have a major impact on the burden of diarrhoeal diseases.
\end{abstract}

Keywords: Diarrhoea, under five, water quality, WaSH, resettlement colony, Delhi.

\section{Introduction}

Diarrhoeal diseases are an outcome of unsafe drinking water and unavailability of water for proper WaSH (water, sanitation and hygiene) practices [1]. It is the second leading cause of death among children under five years of age [1]. Unsafe drinking water, improper sanitation and hand hygiene practices accounts for 525,000 under five deaths globally and every year about 1.7 billion cases are reported [1]. The burden of diarrhoeal diseases is widespread in developing and low-income countries [2]. The highest rates of under five mortality due to diarrhoea were recorded in sub-Saharan Africa and South Asia, with India and Nigeria accounting for $42 \%$ of the total deaths [2]. In India, diarrhoea is responsible for $13 \%$ of all deaths per year in children aged 0-5 years killing an estimate of 300,000 children each year [3] and was found to be more prevalent in children belonging to low socioeconomic status [4].

In 2015, 2.1 people were found to be living without safely managed drinking water services, globally [5] and according to World Health Organization/United Nations Children's Fund resource report about 90\% of diarrhoeal cases are due to contaminated water [6] and in India, about $70 \%$ of the water supply was found to be seriously polluted with sewage effluents and it ranked $10^{\text {th }}$ among 122 nations in terms of unavailability of water to its citizens [6].

Access to safe water not only depends on the supply of treated water but also on the continuous supply of water, which plays a vital role in ensuring water quality [7]. Intermittent water supply aids the degradation of the quality of water because it results in low supply pressure and as a consequence, there is risk of in-pipe recontamination,

thereby increases the chances of water borne diseases [7]. The point-of-use of water has the potential to become contaminated even if water has been treated [6]. The report published by World Health Organization and UNICEF stated that only $33 \%$ of the Indian households treat their drinking water even though it could be bacterially contaminated and only one-fourth of the Indian population have drinking water services on their premises [6].

People residing in resettlement colonies faces with the problem of inaccessibility to clean and affordable drinking water, inadequate sanitation and hygiene practices and garbage disposal [8]. Also, the problem of illiteracy, poor housing conditions and unemployment apart from disposing the population to other air-borne diseases also disposes them off to 
water borne diseases [8]. Inadequate sanitation is estimated to cause 280,000 diarrhoeal deaths worldwide and in India most communicable diseases are water and sanitation related [6]. Open defecation and inadequacy of proper sanitation facilities directly have a negative impact on the health of individuals [9]. In this resettlement colony, it was found that $40 \%$ resorted to open defecation, $8 \%$ constructed small toilets in their houses and 52\% used community toilets available in their area [9]. There is conclusive evidence to show that providing safe water source is not enough to reduce the incidence of diarrhoea [6].

Hand washing is one of the most effective ways of preventing the spread of diarrhoeal diseases. Water alone is not always sufficient to remove the pathogens from hands. Soap, a disinfecting and cleansing agent when used with water can help remove pathogens from hands [6]. The hygiene portion of WaSH (water, sanitation and hygiene) strategy focuses on implementing healthy habits in communities where they are not practiced or where they are not commonly practiced [6]. Unless good hygiene practices are fully understood and adopted as an everyday practice, toilets may not be used, water may still be contaminated by handling it with dirty hands and diarrhoea would still be prevalent [6].

Sustainable Development Goal target 6.1 calls for universal and equitable access to safe and affordable drinking water and improve health of one and all [5]. Although India accounts for over 100,000 under five deaths due to diarrhoea annually, the death rates due to the same is dropping much faster than that compared to the global rate [2]. Diarrhoeal deaths have dropped by $43.2 \%$ in India between 2005 and 2015, whereas the global rate drop was 34.3\% [2].

In the current scenario, diarrhoea is emerging as the major health issue is the capital as more than 500,000 cases were reported in 2017-2018 as per the data collected [2]. There has been increase in complaints relating to water quality and water contamination which rose from 27,227 in 2015 to 33,884 in 2017, with 24\% rise [2]. Each diarrhoeal episode deprives the child of the nutrients required for the body to grow and the poor health condition of the capital could be the reflection of the entire country.

\section{Material and methods}

The study was approved by the Ethical Committee of Lady Hardinge Medical College (LHMC), New Delhi and data collection was conducted from January 2018 to December 2018. The study conducted was a community based crosssectional study carried out in Kalyanpuri, a resettlement colony located in East Delhi. It is one of the field practice area attached to the Urban Health Center of the Department of Community Medicine, LHMC. The houses in this area semiattached/attached and each house being constructed on 25 square meters of land. The drinking water supply in these areas are either piped water supply connected to households, public tap water or drinking water supplied by Delhi Jal Board by water tankers. The piped water supply is intermittent, and water is supplied at $6 \mathrm{am}$ and $6 \mathrm{pm}$ in the evening, for two hours. Sanitary toilets are connected to an underground sewage system and waste water from the kitchen and bathroom are drained through open drains being covered temporarily.

The main unit of study were children under five years of age and as per the sample size calculation the study was conducted among 553 under five children. Fifty percent of the blocks of Kalyanpuri were randomly selected for conducting the study. Approximately equal number of children were identified from all the five blocks and the first household was selected according to serial number of the houses and data was collected till sample size was complete. In houses where there were more than one eligible subject then all the eligible subjects were included in the study and in houses where there were no under five subjects, the next household was selected. Semi-structured pre-tested proforma was designed to collect data on prevalence of diarrhoea and water related human behaviour from responsible care-giver. Diarrhoeal recall period of 14 days was taken for the study.

The second unit of study was constituted by various water sources. MPN count per $100 \mathrm{ml}$ was measured from various point source as well as storage water samples in the household. Water samples were collected from point source as well as drinking water storage containers as per standard guidelines. Assessment of bacteriological quality of water was done in 120 samples, 95 from various water storage containers and 25 from point source. Equal number of samples were collected monthly to assess the bacteriological contamination. Assessment of bacteriological quality of drinking water was done through presumptive coliform count (multiple test tube method), calculating the most probable number. Water sampling procedure and method for bacteriological examination of water was done as per standard protocol of WHO.

The study subjects were found eligible for the study if the study subjects resided in that area for more than a year and if mother/care-givers agreed to give their consent for the study. However, children with compromised immune system or with debilitating diseases or both were not included in the study.

The World Health Organisation has defined diarrhoea as the passage of three or more loose or liquid stools per day (or more frequent passage than is normal for the individual). Frequent passage of formed stool is not diarrhoea nor is the passage of loose, pasty stools by breastfed babies. There are three clinical types of diarrhoea: 
- $\quad$ Acute water diarrhoea- last several hours or days and includes cholera

- $\quad$ Acute bloody diarrhoea- also called dysentery and

- $\quad$ Persistent diarrhoea- last 14 days or longer

Coliform organisms refers to large group of gram-negative, rod shaped bacteria that share several characteristics. The group includes thermotolerant coliform and bacteria of faecal origin, as well as some bacteria that may be isolated from environmental sources [10].

Presumptive (Most Probable Number) count is a method to estimate the number of faecal coliforms in a water sample based on the degree of lactose fermentation by the organisms in the sample [11]. Classification of samples according to WHO criteria for drinking water (guidelines for drinking water quality - water sampling analysis) [11]

\begin{tabular}{|l|l|}
\hline Grade & Presumptive count (per 100ml) \\
\hline Excellent & 0 \\
\hline Satisfactory & $1-3$ \\
\hline Suspicious & $4-10$ \\
\hline Unsatisfactory & $>10$ \\
\hline
\end{tabular}

Statistical analysis was done using SPSS version 25. Chi-square test was done to test the association of water quality with diarrhoea. $\mathrm{p}$-value of $<0.05$ was considered statistically significant.

\section{Results}

Table 1: Sociodemographic profile of study subjects.

\begin{tabular}{|c|c|c|}
\hline Socio-demographic characteristics & & Percentage \\
\hline 1. Age in months & Frequency & $26.3 \%$ \\
\hline $0-12$ & 147 & $22.2 \%$ \\
\hline $13-24$ & 124 & $21.6 \%$ \\
\hline $25-36$ & 121 & $13.6 \%$ \\
\hline $37-48$ & 76 & $16.3 \%$ \\
\hline $49-60$ & 91 & $60.4 \%$ \\
\hline 2. Sex $\quad$ & 259 & $53.7 \%$ \\
\hline Male & 300 & $1.2 \%$ \\
\hline Female & & $38.8 \%$ \\
\hline Socioeconomic status & 7 & $55.6 \%$ \\
\hline Upper middle & 217 & $4.4 \%$ \\
\hline Lower middle & 311 & \\
\hline Lpper lower & 24 & \\
\hline
\end{tabular}

Nearly $70 \%$ of the study subjects belonged to the age group of 0-36 months. Mean age of the study subjects was $31 \pm 16$ months. $46.3 \%$ were males and $53.7 \%$ were females. Majority $(94.4 \%)$ of the families belonged to upper lower socioeconomic status (38.8\%) and lower middle socioeconomic status (55.6\%). 
Table 2: Prevalence of diarrhoea among under five children according to sociodemographic factors.

\begin{tabular}{|c|c|c|c|c|}
\hline $\begin{array}{c}\text { Socio-demographic } \\
\text { characteristics }\end{array}$ & \multirow[t]{2}{*}{ Frequency } & \multirow{2}{*}{$\begin{array}{c}\text { Children suffered } \\
\text { from diarrhoea }\end{array}$} & \multirow{2}{*}{$\begin{array}{l}\text { Prevalence of } \\
\text { diarrhoea }\end{array}$} & \multirow[t]{2}{*}{ Remarks } \\
\hline Age in months & & & & \\
\hline $0-12$ & 147 & 31 & $21.1 \%$ & \\
\hline $13-24$ & 124 & 71 & $57.3 \%$ & \\
\hline $25-36$ & 121 & 62 & $51.2 \%$ & \\
\hline $37-48$ & 76 & 34 & $44.7 \%$ & \\
\hline $49-60$ & 91 & 27 & $29.7 \%$ & \\
\hline \multicolumn{4}{|l|}{ Sex } & \\
\hline Male & 259 & 108 & $41.7 \%$ & \\
\hline Female & 300 & 117 & $39 \%$ & \\
\hline \multicolumn{5}{|l|}{$\begin{array}{c}\text { Socioeconomic } \\
\text { status }\end{array}$} \\
\hline Upper middle & 7 & 1 & $14.3 \%$ & \multirow{4}{*}{$\begin{array}{l}\chi^{2}=14.4 \text { d.f of } 3 \\
\text { and } \\
p<0.002\end{array}$} \\
\hline Lower middle & 217 & 84 & $38.7 \%$ & \\
\hline Upper lower & 311 & 122 & $39.2 \%$ & \\
\hline Lower & 24 & 18 & $75 \%$ & \\
\hline
\end{tabular}

The overall diarrhoeal prevalence was found to be $40.2 \%$. highest prevalence of diarrhoea was found to be in children belonging to 13-24 months of age (57.3\%) followed by children belonging to 25-36 months of age (51.2\%). The prevalence of diarrhoea was found to be the least in children belonging to $0-12$ months of age (21.1\%). The prevalence of diarrhoea was found to be higher in males (41.7\%) as compared to females $(39.0 \%)$.

It was observed that the prevalence of diarrhoea was to be the highest among children belonging to lower socioeconomic status (75.0\%) followed by children belonging to upper lower socioeconomic status (39.2\%) and lower middle socioeconomic status (38.7\%).

It was observed that $26.7 \%$ of the mothers were illiterate, $47.0 \%$ had received primary education and $26.3 \%$ of the mothers had received education middle school and above.

Table 3: Relationship of MPN index with the type of storage vessel used.

\begin{tabular}{|c|c|c|c|c|c|c|c|c|}
\hline \multirow{3}{*}{$\begin{array}{l}\text { Drinking water } \\
\text { storage vessel }\end{array}$} & \multicolumn{8}{|c|}{ MPN Index } \\
\hline & \multicolumn{2}{|c|}{$\begin{array}{l}\text { Satisfactory } \\
\text { (1-3 MPN count) }\end{array}$} & \multicolumn{2}{|c|}{$\begin{array}{l}\text { Suspicious } \\
\text { (4-10 MPN count) }\end{array}$} & \multicolumn{2}{|c|}{$\begin{array}{l}\text { Unsatisfactory } \\
\text { (>10 MPN count) }\end{array}$} & \multicolumn{2}{|c|}{ Total } \\
\hline & No & $(\%)$ & No & $(\%)$ & No & $(\%)$ & No & $(\%)$ \\
\hline Bucket & 0 & & 5 & $(41.6)$ & 7 & $(58.4)$ & 12 & $(12.6)$ \\
\hline Plastic cans & 3 & $(37.5)$ & 3 & $(37.5)$ & 2 & $(25.0)$ & 8 & $(8.4)$ \\
\hline $\begin{array}{l}\text { Commercially } \\
\text { available containers }\end{array}$ & 2 & $(23.6)$ & 6 & $(66.6)$ & 1 & $(11.1)$ & 9 & $(9.4)$ \\
\hline Plastic bottles & 9 & $(23.6)$ & 11 & $(23.9)$ & 18 & $(47.4)$ & 38 & $(40.0)$ \\
\hline Plastic jugs & 4 & $(20.0)$ & 7 & $(35.0)$ & 9 & (24.3) & 20 & (21.1) \\
\hline Earthen pitcher & 4 & $(50.0)$ & 4 & $(50.0)$ & 0 & & 8 & ( 8.4) \\
\hline Total & 22 & $(23.2)$ & 36 & $(37.8)$ & 37 & $(38.9)$ & 95 & $(100)$ \\
\hline
\end{tabular}

Out of the total 95 samples, $12.6 \%$ of the samples were stored in buckets, $8.4 \%$ were stored in plastic cans, $9.4 \%$ were those of commercially available containers, $40.0 \%$ were those of plastic bottles, $21.1 \%$ were those of plastic jugs and $8.4 \%$ were those of earthen pitcher.

None of the samples collected for the study was found to be that of excellent quality, $23.2 \%$ were found to be Satisfactory, $37.8 \%$ were found to be suspicious and $38.9 \%$ were found to be Unsatisfactory.

Table 4: Relationship of diarrhoea with mean MPN count of the type of storage vessel used.

\begin{tabular}{|l|c|c|}
\hline Primary water storage vessel & Mean MPN $\mathbf{S}$ S.D & Prevalence of diarrhoea (\%) \\
\hline Bucket & $83.4 \pm 65.2$ & 66.6 \\
\hline Plastic cans & $12.8 \pm 10.4$ & 25.0 \\
\hline Commercially available containers & $13.07 \pm 10.86$ & 11.1 \\
\hline Plastic bottles & $13.0 \pm 10.1$ & 28.9 \\
\hline Plastic jugs & $14.0 \pm 14.2$ & 45.0 \\
\hline Earthen pitcher & $14.6 \pm 11.7$ & 0 \\
\hline
\end{tabular}


The highest mean MPN count was found in buckets $(83.4 \pm 65.2)$ and the diarrhoea prevalence among under five children was also observed to be highest in this group of children (66.6\%).

Table 5: Relationship of MPN index with method of purification of water.

\begin{tabular}{|c|c|c|c|c|c|c|c|c|}
\hline \multirow{3}{*}{ Method } & \multicolumn{8}{|c|}{ MPN Index } \\
\hline & \multicolumn{2}{|c|}{$\begin{array}{c}\text { Satisfactory } \\
\text { (1-3 MPN count) }\end{array}$} & \multicolumn{2}{|c|}{$\begin{array}{c}\text { Suspicious } \\
\text { (4-10 MPN count) }\end{array}$} & \multicolumn{2}{|c|}{$\begin{array}{l}\text { Unsatisfactory } \\
\text { (>10 MPN count) }\end{array}$} & \multicolumn{2}{|c|}{ Total } \\
\hline & No & $(\%)$ & No & $(\%)$ & & $(\%)$ & No & $(\%)$ \\
\hline Boiling & 0 & & 0 & & 2 & (100) & 2 & (2.1) \\
\hline Domestic filter & 6 & $(23.1)$ & 14 & $(53.8)$ & 6 & (23.1) & 26 & $(27.4)$ \\
\hline $\begin{array}{l}\text { Commercially } \\
\text { available filtered } \\
\text { water }\end{array}$ & 8 & $(25.8)$ & 9 & $(29.0)$ & 14 & $(45.2)$ & 31 & $(32.6)$ \\
\hline No method used & 0 & & 17 & $(47.1)$ & 19 & $(52.7)$ & 36 & (37.9) \\
\hline
\end{tabular}

Only 2 samples of drinking water was collected where drinking water boiled, but both the samples were found to be bacteriologically contaminated and was found to be unsatisfactory (100\%). One-third of the water samples collected from domestic filters were found to be unsatisfactory. Out of the total, $36(37.9 \%)$ water samples were not subjected to any form of purification method and were found to be either suspicious $(47.1 \%)$ or unsatisfactory $(52.7 \%)$.

Table 6: Relationship of MPN count with diarrhoea.

\begin{tabular}{|l|l|l|l|l|l|}
\hline \multirow{2}{*}{\begin{tabular}{c} 
Children suffered with \\
\multirow{2}{*}{$\begin{array}{c}\text { diarrhoea } \\
(\mathbf{n = 9 5})\end{array}$}
\end{tabular}} & \multicolumn{3}{|c|}{ MPN } & \multirow{2}{*}{$\begin{array}{c}\text { Total } \\
(\mathbf{n = 9 5})\end{array}$} & \multirow{2}{*}{ Remarks } \\
\cline { 2 - 5 } & Satisfactory & Suspicious & Unsatisfactory & & $\chi^{2}=12.5$ \\
$\mathrm{p}<0.02$ \\
\hline Yes & $4(11.1 \%)$ & $10(27.7 \%)$ & $22(61.1 \%)$ & 36 & \\
\hline No & $18(30.5 \%)$ & $26(44.1 \%)$ & $15(25.4 \%)$ & 59 & \\
\hline
\end{tabular}

Out of the total 36 children who suffered from diarrhoea, $61.1 \%$ of the children were consuming water which was unsatisfactory, $27.7 \%$ of the children were consuming water which was of suspicious quality and only $11.1 \%$ of the children were consuming water fit for human consumption. Fifty-nine children who did not suffer from diarrhoea at the time of data collection, $30.5 \%$ consumed which was satisfactory, $44.1 \%$ and $25.4 \%$ consumed water which was suspicious and unsatisfactory, respectively.

\section{Discussion}

The prevalence of diarrhoea in the resettlement colony was found to be $40.2 \%$ which was observed to be three times higher than the prevalence of diarrhoea as reported by NFHS-4 (2015-2016) [12] of 9\%. High prevalence of diarrhoea was also found in studies conducted by Balakrishnan Kalakheti et al [13], Chilambwe $\mathrm{M}$ et al [14] and Katharina Diouf et al [15] in which the prevalence of diarrhoea was found to be $40.2 \%, 40.5 \%$ and $32.6 \%$, respectively.

The trend of diarrhoea was found to be similar in both the sexes and also among different age groups in which the prevalence of diarrhoea was found to be the highest among children belonging to 13-24 months of age and least among children belonging to 0-12 months of age (table 2). The findings of this study was found to be similar to the study conducted by Wondwoson Woldu et al [16], Kunal Kanti Majumdar et al [17], Enakshi Ganguly et al [18] and Avisek Gupta et al [19], in which the prevalence of diarrhoea was found to be the highest among children belonging to the age group of 12-24 months. The high prevalence of diarrhoea in this age group could be related to the exposure of children to microorganisms while crawling on the floor, thereby causing diarrhoea. $\{10,8,63,64\}$. According to this study, it could also be attributed to the practice of weaning in which water and food which are contaminated as a result of improper sanitation and hand hygiene practices and unsafe water storage practices, are given to the children leading to the occurrence of diarrhoea among study subjects.

One of the best established epidemiological finding is that the prevalence of some diseases are strongly influenced by economic factors. These diseases in developing countries can be considered as "diseases of poverty". In this study the prevalence of diarrhoea was also found to be the highest among children belonging to lower socioeconomic status (14.3\% in upper middle socioeconomic class versus $75.0 \%$ in lower socioeconomic classes). Prevalence of diarrhoea was found to be more prevalent in children whose mothers were illiterate $(42.7 \%)$, followed by those children whose mothers had 
only received primary education $(40.8 \%)$, while children whose mothers were educated high school and above showed the prevalence of diarrhoea of $6.22 \%$. The finding of which was found to be statistically significant $(\mathrm{p}<0.0001)$ and similar findings were reported by studies conducted by Atalay Getachew et al [20], Farzana Ferdous et al [21] and Ashwani kumar et al [22].

Water related diseases caused by insufficient water supply, contamination of water due to poor sanitation and hygiene practices, poor living conditions causes 3.4 million deaths a year, mostly in children [23]. The water samples collected from point source were found to be satisfactory for human consumption, whereas out of the 95 water samples collected from point-of-use, 36 samples (37.8\%) were found to be suspicious, 37 (38.9\%) were found to be unsatisfactory. The MPN count of $>3 / 100 \mathrm{ml}$ renders water unfit for human consumption and considering this fact only $23.2 \%$ of the water samples were found to be satisfactory and none found to be excellent with MPN count of 0 (table 3).

The mean MPN count of water stored in buckets was found to be $83.4 \pm 65.2$, which was found to be the highest (table 4) and the prevalence of diarrhoea was found to be $66.6 \%$, throwing light on the fact that faulty water storage practices, sanitation and hand hygiene practices needs to be looked into and proper WaSH (Water, Sanitation and Hygiene) practices needs to be followed by every individual of the family to bring down the prevalence of diarrhoea. A similar study conducted by Malhotra S et al [24] on bacteriological analysis of drinking water from different schools in Northern India showed that among the total 903 water samples taken from various water reservoirs of the schools, both government and private, $39.8 \%$ of the water samples were unsatisfactory for consumption, $26.1 \%$ were satisfactory and $34.1 \%$ were found to be of excellent quality. Also the study conducted by Muhammad Saeed et al [25] on bacteriological quality of water showed that out of the total 530 water samples, 197 (37.2\%) samples were found to be contaminated. Similar findings were also observed in studies conducted by Balaram et al [26] and Ayse Ercumen et al [27].

The maintenance of sanitation and hygiene is vital for human health. The importance of the same should be borne in mind even after water has been subjected to purification. In this study it was found that even after water had been subjected to boiling yet the water sample on being subjected to test was found to be $100 \%$ unsatisfactory (table 5). Sanitation and hygiene practices are to be blamed for and also the faulty water storage practices that usually follow (i.e., boiling water in different container and storing it in another) renders water unsatisfactory for human consumption. Similarly, frequency of cleaning the filters should be borne in mind. The samples of water which were not subjected to any form of purification method was found to be suspicious $(47.1 \%)$ and unsatisfactory $(52.7 \%)$. Study conducted by Nazia et al [28] showed that water quality interventions conducted at the point-of-use significantly decreased the prevalence of diarrhoea by $40.0 \%$ (53.0\% decrease with respect to water filtration and $31.0 \%$ with respect to water disinfection). No effect of water quality interventions at source on risk of diarrhoea was observed [28].

\section{Conclusion and Recommendation}

Improper sanitation, hygiene practices and low socioeconomic status greatly influences the occurrence of diarrhoea and as a result the prevalence of diarrhoea was found to be high (40.2\%) among children under five years of age living in this resettlement colony. Though aware of the WaSH (Water, Sanitation and Hygiene) practices yet people living in this area fail to develop behaviour change and adopt these practices. Therefore, it is of utmost importance that every individual follow good hygiene and sanitation practices, its importance be known and health education be given to bring about behaviour change. The Sustainable Development Goal 6 states the importance of clean water and sanitation for achieving good health therefore, sanitary survey of household water storage containers to find out the bacteriological quality of drinking water, method of water treatment required, if any, needs to be performed on a regular basis, for decreasing the burden of diarrhoea.

\section{Limitation}

Microbiological assessment of drinking water quality of all the sources neither all household level of storage containers could be done since this study was done by a single investigator. The distance from the field of study to Microbiology lab was more than $20 \mathrm{~km}$, therefore the time lag between sample collection and culture preparation could have influenced the study.

\section{Financial support and sponsorship}

Nil.

\section{Conflict of interest}

There are no conflict of interest. 


\section{References}

[1] UNICEF, Diarrhoea. Why children are still dying and what can be done. New York: UNICEF. 2009

[2] WHO. Diarrhoeal disease: Burden. Global burden. Geneva: WHO 2017

[3] S. Lakshminarayanan, R. Jayalakshmy, "Diarrhoeal diseases among children in India: Current scenario and future perspectives," Journal of natural science, biology and medicine, vol. 1, no. 24, 2015.

[4] C. J. Murray, A. D. Lopez, "Measuring global health: motivation and evolution of the Global Burden of Disease Study," The Lancet, vol. 390, pp. 1460-4, 2017.

[5] R. Connor, The United Nations world water development report 2015: water for a sustainable world. UNESCO Publishing; 2015 Mar 23.

[6] WHO/UNICEF, Progress on Drinking Water, Sanitation and Hygiene. WHO/UNICEF. 2017.

[7] B. K. Satapathy, "Safe drinking water in slums," Economic \& Political Weekly, vol. 49, no. 24, p. 51, 2014.

[8] D. Sur, B. Manna, A. K. Deb, J. L. Deen, M. C. Danovaro-Holiday, L. Von Seidlein, J. D. Clemens, S. K. Bhattacharya, "Factors associated with reported diarrhoea episodes and treatment-seeking in an urban slum of Kolkatta, India," Journal of Health, Population and Nutrition, vol. 1, pp. 130-8, 2004.

[9] Delhi Urban Slum Improvement Board, In Situ development of Kalyanpuri slums, Delhi.

[10] N. J. Ashbolt, W. O. Grabow, M. Snozzi, 13 Indicators of microbial water quality.

[11] WHO, Guidelines for drinking-water quality., $4^{\text {th }}$ edition, incorporating the $1^{\text {st }}$ addendum. Geneva: WHO; 2017

[12] N. Dhirar, S. Dudeja, J. Khandekar, D. Bachani, "Childhood Morbidity and Mortality in India- Analysis of National Family Health Survey 4 (NFHS-4) Findings,” Indian paediatrics, vol. 55, no. 4, pp. 335-8, 2018.

[13] B. Kalakheti B, Panthee K, Jain KC. Risk Factors of Diarrhea in Children Under Five Years in Urban Slums. Journal of Lumbini Medical College. 2016 Dec 30; vol. 4, no. 2, pp. 94-8.

[14] M. Chilambwe, D. Mulenga, S. Siziya "Diarrhoea Prevalence in Under-Five Children in Two Urban Populations Setting of Ndola, Zambia: An Assessment of Knowledge and Attitude at the Household Level," J Infect Dis Ther., vol. 3, no. 227, pp. 2332-0877, 2015.

[15] K. Diouf, P. Tabatabai, J. Rudolph, M. Marx, "Diarrhoea prevalence in children under five years of age in rural Burundi: an assessment of social and behavioural factors at the household level," Global health action, vol. 7, no. 1, p. 24895, 2014.

[16] W. Woldu, B. D. Bitew, Z. Gizaw, "Socioeconomic factors associated with diarrheal diseases among under-five children of the nomadic population in northeast Ethiopia," Tropical medicine and health, vol. 44, no. 1, p. 40, 2016.

[17] K. K. Majumdar, "Health impact of supplying safe drinking water containing fluoride below permissible level on flourosis patients in a fluoride-endemic rural area of West Bengal," Indian journal of public health, vol. 55, no. 4, p. 303, 2011.

[18] E. Ganguly, P. K. Sharma, C. H. Bunker, "Prevalence and risk factors of diarrhea morbidity among under-five children in India: A systematic review and meta-analysis," Indian journal of child health, vol. 2, no. 4, p. 152, 2015.

[19] A. Gupta, T. K. Roy, G. Sarker, B. Banerjee, S. Ghosh, R. Pal, "Determinants of contraceptive practices among eligible couples of urban slum in Bankura District, West Bengal," Journal of family medicine and primary care, vol. 3, no. 4, p. 3882, 2014.

[20] A. Getachew, T. Guadu, A. Tadie, Z. Gizaw, M. Gebrehiwot, D. H. Cherkos, M. A. Menberu, T. Gebrecherkos, "Diarrhea Prevalence and Sociodemographic Factors among Under-Five Children in Rural Areas of North Gondar Zone, Northwest Ethiopia," International journal of paediatrics, 2018.

[21] F. Ferdous, S. K. Das, S. Ahmed, F. D. Farzana, J. R. Latham, M. J. Chisti, A. I. Ud-Din, I. J. Azmi, K. A. Talukder, A. S. Faruque, "Severity of diarrhea and malnutrition among under five-year-old children in rural Bangladesh," The American journal of tropical medicine and hygiene, vol. 89, no. 2, pp. 223-8, 2013.

[22] A. Kumar, K. C. Das, "Drinking water and sanitation facility in India and its linkages with diarrhoea among children under five: evidences from recent data," Int J Humanit Soc Sci Invent., vol. 3, pp. 50-60, 2014.

[23] S. K. Malhotra, S. Malhotra, G. S. Dhaliwal, A. Thakur, "Bacteriological study of pyodermas in a tertiary care dermatological center," Indian journal of dermatology, vol. 57, no. 5, p. 358, 2012.

[24] S. Malhotra, S. K. Sidhu, P. Devi, "Assessment of bacteriological quality of drinking water from various sources in Amritsar district of northern India," The Journal of Infection in Developing Countries, vol. 9, no. 08, pp. 844-8, 2015.

[25] M. S. Anwar, S. H. Lateef, G. M. Siddiqi, "Bacteriological quality of drinking water in Lahore," Biomedica., no. 1, pp. 66-9, 2010. 
[26] M. Thummakomma, P. Ramesh, M. Reddy, B. Balram, "Utility Of Implementing Integrated Management Of Neonatal And Childhood Illness (IMNCI) Algorithm In A Tertiary Care Hospital For The Young Infants Of Age 0-2 Months," Breast., vol. 25, no. 29, pp. 74-3.

[27] A. Ercumen, A. M. Naser, L. Unicomb, B. F. Arnold, J. M. Colford Jr., S. P. Luby, "Effects of source-versus household contamination of tubewell water on child diarrhea in rural Bangladesh: a randomized controlled trial," PloS one., vol. 10, no. 3:e0121907, 2015.

[28] N. Darvesh, J. K. Das, T. Vaivada, M. F. Gaffey, K. Rasanathan, Z. A. Bhutta, "Water, sanitation and hygiene interventions for acute childhood diarrhea: a systematic review to provide estimates for the Lives Saved Tool," BMC public health, vol. 17, no. 4, p.776, 2017. 